\title{
Towards National Evidence-Informed Practice Guidelines for Canadian EMS: Future Directions
}

\section{Vers des directives nationales de pratiques éclairées par les données probantes pour les SMU au Canada : orientations pour l'avenir}

\author{
路 \\ JAN L. JENSEN, ACP, BSC, MAHSR \\ Dalhousie University, Division of Emergency Medical Services \\ Emergency Health Services Nova Scotia \\ Halifax, NS \\ THOMAS DOBSON, ACP, BA \\ Emergency Health Services Nova Scotia \\ Halifax, NS
}

THE CANADIAN EMS QUALITY IMPROVEMENT COMMITTEE

\begin{abstract}
In emergency medical services (EMS), like other areas of healthcare, a substantial knowledgeto-action gap exists between the results of research and widespread use in clinical practice. This paper reports on a national workshop held to develop a process for creating National EMS Evidence-Informed Clinical Guidelines in an attempt to improve knowledge translation. We discuss the lessons learned from the workshop and next steps in developing the guidelines. This process and its lessons are generalizable to other areas of healthcare seeking to develop evidence-based guidelines. National EMS Evidence-Informed Guidelines will likely be a meaningful knowledge translation activity for Canadian EMS.
\end{abstract}

\section{Résumé}

Dans les services médicaux d'urgence (SMU), comme pour les autres secteurs des services de santé, il existe un important fossé entre les résultats de recherche (connaissances) et leur 
utilisation généralisée dans la pratique clinique (actes). Cet article fait état d'un atelier national organisé pour mettre au point un processus de création de directives cliniques nationales éclairées par les données probantes et destinées aux SMU, et ce dans le but d'améliorer la transposition des connaissances. Nous discutons des leçons retenues de l'atelier et des prochaines étapes pour la conception des directives. Ce processus et les leçons peuvent être appliqués à d'autres secteurs des services de santé où l'on souhaite mettre au point des directives fondées sur les données probantes. Ces directives nationales éclairées par les données probantes représenteront probablement une importante activité de transposition des connaissances pour les SMU au Canada.

\section{There is a movement afoot in North American emergency medical ser- vices (EMS) systems to base clinical protocols on the best research evidence avail- able (Brown et al. 1999; Myers et al. 2008). The purpose is to minimize the time} between publication of the research results and their implementation into widespread clinical practice, an interval known as the knowledge-to-action gap (Graham et al. 2006). Examples of initiatives working towards this goal are the ongoing Canadian Prehospital Evidence-based Protocols (PEP) project (Jensen et al. 2009) and the 2008 US conference, "From Evidence to EMS Practice: Building the National Model," hosted by federal EMS regulators (National Highway Traffic Safety Administration et al.2008). Cone (2007) clearly highlighted the issue with his slogan that EMS must "get the evidence straight, and get the evidence used." Similarly, Myers and colleagues stated that EMS system quality must be evaluated with indicators that are based on research evidence and not just traditional operational data that have little clinical meaning (Myers et al. 2008).

EMS administration and medical oversight is fairly heterogeneous across Canada, but to a lesser extent than in the United States, in the sense that EMS systems in each Canadian province and territory have generally evolved independently of one another. Typically, services are regulated by provincial departments or ministries of health, and are operated by municipalities, private companies or health authorities (EMSCC 2006). Paramedic scopes of practice in each jurisdiction differ considerably from one another. These variances make sharing continuing quality improvement (CQI) data across services difficult. However, there is a trend towards more EMS regulation and operation by either provincial governments or regional health authorities, as opposed to individual services (EMSCC 2006). For example, in the province of Alberta, EMS delivery has recently transitioned from municipal to provincial jurisdiction. This move increased EMS integration within the healthcare system, and includes the transfer of governance and funding of EMS services and the consolidation of dispatch services (Alberta Health Services 2009). Increasing uniformity will potentially aid data sharing and standard practices among EMS systems. Although Canada is a geographically vast country, there are several factors that make it possible to establish National EMS Evidence- 
Informed Clinical Guidelines (hereafter called "EMS Guidelines") that are generalizable to most systems. These include, but are not limited to, the relative homogeneity of EMS systems, legislation, standards of care and provision of paramedic education.

In Canada, paramedic leaders specializing in CQI have met annually in recent years to open lines of communication and share best practices across the country. The committee represents the following provinces: Nova Scotia, New Brunswick, Prince Edward Island, Quebec, Ontario, Saskatchewan, Alberta and British Columbia, with other provinces and systems invited. The second meeting of the Canadian EMS Quality Improvement committee occurred October 6-7, 2009 in Ottawa, Ontario, Canada. In the previous year, the group identified a need to focus on using research evidence to guide paramedic clinical practice. A one-day workshop was developed in response (Table 1 ). The workshop planning team decided the committee would work through the process of developing three EMS Guidelines.

TABLE 1. Workshop topics

\begin{tabular}{|l|l|}
\hline & Introduction to Meeting \\
\hline I & Introduction to Workshop: Creating National Evidence-Informed Guidelines \\
\hline II & Clinical Practice Guidelines \\
\hline III & Local Protocol Development \\
\hline IV & Creating National Evidence-Informed Guidelines \\
\hline V & Evaluate Process \\
\hline
\end{tabular}

\section{Objective}

This paper will describe the methods we used to develop national evidence-informed guidelines, the lessons learned and next steps identified. Readers may appreciate the similarities between developing guidelines for Canadian EMS systems and their own health settings, and may hopefully discover tools that are applicable to them.

\section{"Evidence-Informed" National Guidelines}

The work of the committee was guided by the principles of evidence-based practice: making decisions using the best available research evidence, clinical experience and expertise, and patient values (Sackett et al. 1996). The term "evidence-informed" was used, which captures the original and true meaning of evidence-based medicine: that research must play an important role in guiding clinical practice, but other evidence, including experiences and local values, must also be equally considered [(Dr. Jeremy Grimshaw, Canada Research Chair in Health Knowledge Transfer and Uptake, personal communication, September 29, 2009).]

\section{Guidelines}

In most Canadian EMS systems, clinical protocols or medical directives dictate paramedic care. EMS medical directors create these documents, based on existing norms and standard 
practice, relying on their own judgment on what will be most successful in the local system. Protocols are often presented in algorithm format and are analogous to "practice standards," which are definitions of the correct practice, with few treatment options, intended to be followed explicitly (Eddy 1990). Paramedics generally commit their services' protocols to memory and, in clinical practice, fit their patient to the most applicable protocol (although this is hardly an exhaustive explanation of paramedic clinical decision-making). Protocols define both treatment and non-clinical decisions, such as when to consult a medical director. Committee members identified the following triggers for creation or revision of a protocol: medical director opinion, paramedic feedback, CQI data and/or the results of clinical auditing, adverse events, the release of new guidelines (such as the 2010 Resuscitation Guidelines for CPR), practice trends across the country and the results of research (especially local studies).

Guidelines, in contrast to protocols, allow for more treatment flexibility (Field and Lohr 1992). They are statements about specific clinical problems and are intended as references, not rigid criteria. By nature, guidelines should accommodate a variety of treatment settings and are an application tool, derived from synthesis of the best available research.

It is difficult for individual medical directors or CQI paramedics to stay abreast of all the research applicable to EMS care, which is by nature broad, varied and continuously updated. Owing to the substantial undertaking required to develop local protocols solidly based on current, applicable research evidence, the committee determined that a set of EMS Guidelines would be desirable, if not necessary. A national group effort should be coordinated to assume the development of such guidelines, which would help to standardize pre-hospital clinical care across the country and permit meaningful comparisons across EMS systems.

\section{Workshop Proceedings}

Committee members were divided into three small groups, each consisting of four members. Each group was assigned a clinical condition several weeks prior to the meeting and was e-mailed a selection of research articles on interventions specific to their condition (retrieved from the PEP database), an existing clinical practice guideline (CPG) and a collection of approximately 10 current EMS protocols from services from across Canada. The three clinical conditions were asthma, ST-elevation myocardial infarction (STEMI) and congestive heart failure (CHF). These conditions were chosen because relevant research evidence and published CPGs are available, and they are high-acuity conditions often attended to by paramedics in the EMS setting.

Upon arrival at the workshop, each member signed a conflict of interest declaration form, in the spirit of transparency. The workshop consisted of a mix of lectures, small group working sessions and large group roundtable discussions (Table 1). Small group sessions were part of the day to allow members to do some of the work in creating the guideline, and to develop specific issues for discussion. After an introductory lecture on the workshop process and on using evidence in EMS practice, the small groups broke out to analyze the research articles they received. The next small group session was focused on the CPG. Members discussed 
whether the guideline addressed the EMS setting and interventions specific to pre-hospital care. They also determined whether the guideline could be used without modification. Each group then developed a draft guideline, using the research articles, the published CPG and Canadian EMS protocols to guide them. The large group discussed their progress at each step, and identified barriers and facilitators to the process. The groups continued to refine their guidelines by e-mail communication after the workshop concluded.

\section{Lessons Learned and Next Steps}

Rarely can primary research be put into clinical practice without some sort of synthesis, appraisal and tailoring (Graham et al. 2006; Huberman 1987). The committee determined that the following steps are necessary to develop a set of evidence-informed clinical guidelines:

- locating relevant evidence from various sources (research studies, published guidelines and experiences from EMS systems);

+ $\quad$ synthesizing the evidence;

+ developing the guidelines;

+ implementing them into practice; and

- evaluating their uptake (Figure 1).

FIGURE 1. Steps for creating National EMS Guidelines
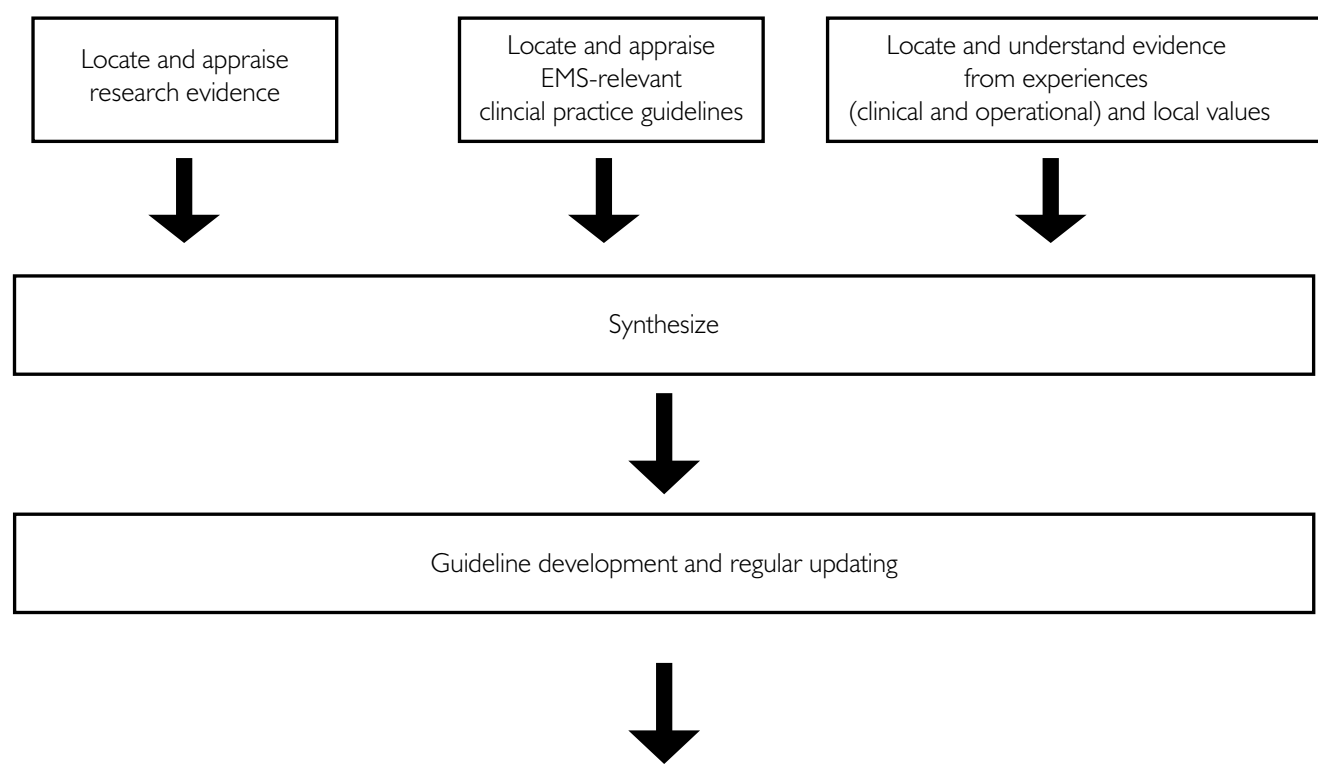

Knowledge translation, implementation and evaluation 
During and upon completion of the workshop, the members discussed each step of the process, identifying lessons learned and next steps to take.

\section{Locating research evidence}

The committee quickly identified that searching for and evaluating all the existing relevant research evidence for a particular clinical condition would be an immense task. They felt limited in their ability to make solid treatment recommendations based on the few research articles they had access to during the workshop. Consensus was reached that for EMS Guidelines to be created and updated regularly, the evidence search and appraisal process would need to be as efficient as possible. The group discussed splitting up the clinical conditions among committee member dyads - ideally, medical director-paramedic pairs, who would be responsible for searching for research and existing CPGs relevant for assigned clinical conditions. To locate studies, reviewers could use the PEP database, which is the most robust and up-to-date evidence base specific to EMS care in Canada, and which is openly available online (http:// emergency.medicine.dal.ca/ehsprotocols/protocols/toc.cfm). The limitation of the PEP database is that it is highly focused on treatment interventions and therefore offers little evidence or few recommendations for communications, assessment or transport interventions. It would be necessary to conduct structured searches of the published and grey literature to find evidence on these aspects of EMS delivery.

\section{The utility of existing guidelines}

CPGs are produced by a variety of groups around the world, including the International Liaison Committee on Resuscitation (ILCOR) (Timerman et al. 2006), the Eastern Association for the Surgery of Trauma (EAST 1998), the Canadian Medical Association Journal (CMAJ 2009) and many others. Guideline repositories exist, such as the US National Guideline Clearinghouse (www.guideline.gov). The relevance of published CPGs to EMS is unknown, but likely varies greatly.

Workshop members reviewed three CPGs for their applicability to Canadian EMS (National Heart, Lung and Blood Institute 2007; Arnold et al. 2006; AHA 2005). One guideline was found to be excessively long. Two guidelines were focused on acute illnesses frequently encountered by paramedics; however, they contained little direction for care that should be delivered in the EMS setting. The group found that one guideline could be used to create a local EMS protocol, but some inference was still required to determine the best timing for interventions. These observations led the committee members to reiterate that a set of EMS Guidelines should address EMS-specific issues much more directly. Existing high-quality CPGs (Brouwers et al. 2010), along with research evidence, should be used as references for the creation of EMS Guidelines.

\section{Guideline creation}

Drafts of EMS Guidelines were created for three clinical conditions. The group identified 
elements that should be included in each guideline to maximize the usefulness of the documents for CQI paramedics, medical directors and field paramedics (Table 2). These elements included a clear definition of the clinical condition and information for each type of EMS intervention: communications (specific information to be gathered by the medical dispatcher or instructions to be given to the 911 caller), assessments (to be undertaken specific to the condition, such as 12-lead electrocardiogram for suspected myocardial infarction), treatments and transport interventions (such as bypassing community hospitals for designated cardiac centres with myocardial infarction patients). The group also determined that quality indicators should be included with each guideline, that is, data points that should be collected by EMS systems to determine whether the guideline is followed appropriately.

TABLE 2. Elements included in National EMS Guidelines

\begin{tabular}{|c|c|c|c|}
\hline Element & Sections & Notes & Examples from Myocardial Infarction Guideline* \\
\hline $\begin{array}{l}\text { Clinical } \\
\text { Condition }\end{array}$ & $\begin{array}{l}\text { Condition } \\
\text { Definitions }\end{array}$ & $\begin{array}{l}\text { A clear description of the clinical condition to } \\
\text { which this guideline refers. } \\
\text { Definitions will outline various levels of } \\
\text { severity of the condition, if applicable. }\end{array}$ & $\begin{array}{l}\text { Acute myocardial infarction (ST-elevation in } 2 \text { or } \\
\text { more leads) }\end{array}$ \\
\hline \multirow[t]{4}{*}{ Interventions } & $\begin{array}{l}\text { Communication } \\
\text { Interventions }\end{array}$ & $\begin{array}{l}\text { Procedures or actions done by the call-taker } \\
\text { or dispatcher, specific to this clinical condition. }\end{array}$ & $\begin{array}{l}\text { Instruct patient to take a baby Aspirin prior to } \\
\text { paramedics' arrival. }\end{array}$ \\
\hline & $\begin{array}{l}\text { Assessment } \\
\text { Interventions }\end{array}$ & $\begin{array}{l}\text { Assessments that should be done, specific } \\
\text { to this clinical condition (i.e., standard } \\
\text { assessment - physical, history and vital signs } \\
\text { need not be listed in the guideline). }\end{array}$ & $\begin{array}{l}\text { Obtain 12-lead electrocardiogram within } 10 \text { minutes } \\
\text { of arrival. }\end{array}$ \\
\hline & $\begin{array}{l}\text { Treatment } \\
\text { Interventions }\end{array}$ & $\begin{array}{l}\text { Each treatment for a specific clinical condition. } \\
\text { All reasonable treatment options should be } \\
\text { included and assigned a recommendation } \\
\text { level. }\end{array}$ & Administer nitroglycerin. \\
\hline & $\begin{array}{l}\text { Transport } \\
\text { Interventions }\end{array}$ & $\begin{array}{l}\text { Transport decisions specific to the clinical } \\
\text { condition. } \\
\text { Routine transport to closest appropriate } \\
\text { facility need not be listed in guideline. }\end{array}$ & Transport to designated cardiac centre (if applicable). \\
\hline $\begin{array}{l}\text { Quality } \\
\text { Indicators }\end{array}$ & & $\begin{array}{l}\text { Defined data points that should be collected } \\
\text { by the EMS system. }\end{array}$ & $\begin{array}{l}\text { Time of first cardiogram obtained. } \\
\text { Time from first cardiogram to definitive treatment. }\end{array}$ \\
\hline
\end{tabular}

The group agreed that the EMS Guidelines would require regular updating at predefined cycles in order to stay abreast of the most recent research evidence. This approach is akin to how ILCOR releases updated resuscitation recommendations every five years (Gazmuri et al. 2007). The exact timing cycle was not determined during this workshop, but is an essential planning point for moving this process forward.

\section{Guideline implementation}

To ensure efficient uptake of the guidelines by systems across the country, the committee agreed that a plan must be developed to promote the EMS Guidelines. In conjunction with making paramedics and medical directors aware the Guidelines exist, end users will require 
education and direction on how to tailor the EMS Guidelines for use in their individual services. Many stakeholders must be considered in the knowledge translation phase, including front-line providers, managers, educators, regulators and EMS medical directors, as well as several key national and regional EMS organizations, such as the EMS Chiefs of Canada, Paramedic Association of Canada, the Society for Prehospital Educators of Canada, the Canadian Association of Emergency Physicians - EMS Committee and others.

It is essential that the uptake and use of the EMS Guidelines be purposively evaluated. This project is an activity in knowledge translation. As such, the effectiveness must be determined, and the process adjusted to make improvements and meet the needs of the users (Graham et al. 2006). An example of this type of monitoring would be to determine the percentage of services in Canada that have used the EMS Guidelines after they are released, over a five- or 10-year period.

\section{Next steps}

For this process to be all-encompassing and a success, the committee identified several next steps. First, it was recognized that key people were not present at the workshop who would play an essential role in various phases of this process, such as medical directors for the guideline location, synthesis and writing phase, and educators and national organizations for the knowledge translation phase. Secondly, this project will require a substantial amount of work and an efficient process for locating, reviewing and synthesizing various forms of evidence (research, existing guidelines and local operational evidence). Clinical areas in which high-quality published CPGs do not currently exist should be considered a priority. Finally, the majority of communication should be undertaken via an online medium, to reduce travel expenditures. A dedicated coordinator and funding are necessary. Stakeholders should be consulted on the best formats in which to release the guidelines to end users, and expertise consulted on how to evaluate the impact of the guidelines on clinical care and continuous quality improvement.

\section{Conclusion}

This workshop brought together a group of EMS CQI leaders from across Canada. It provided a medium to develop a process to create a set of National EMS Evidence-Informed Clinical Guidelines, by making a "dry run" of creating three guidelines. The committee members recognized the importance of getting the research evidence straight with an evidence appraisal process. They forecast a set of EMS Guidelines that would be an effective tool for getting research evidence used in individual EMS systems, to minimize the knowledge-toaction gap. Lessons learned were identified and next steps determined.

\section{ACKNOWLEDGEMENTS}

The Ottawa Paramedic Service hosted this meeting. Committee members were sponsored by their individual services to attend: Donald MacLellan (Island EMS, PEI), Edgar Goulette (Ambulance, NB), Mathieu Hache (Ambulance, NB), Dr. Eli Segal (Urgences-Santé, QC), 
Jan L. Jensen et al.

Claude Desrosiers (Urgences-Santé, QC), Diane Verreault (Urgences-Santé, QC), Jim Harris (Central East Prehospital Program, ON), Jennifer Bionda (Ottawa Paramedic Service, ON), Mike Martin (Ottawa Paramedic Service, ON), Jeff Knight (Ottawa Paramedic Service, ON), Jennifer Wheaton (Alberta Health Services, AB). Thank you to Dr. Eli Segal for his detailed edits to the manuscript.

Correspondence may be directed to: Jan L. Jensen, Dalhousie University, Division of EMS, QE II Health Sciences Centre, 1796 Summer St., Room 3022, Halifax, NS; B3H 3A7; tel.: 902-4942255; e-mail: jljensen@dal.ca.

\section{REFERENCES}

Alberta Health Services. 2009. On the Move. An Update on the EMS Transition in Alberta. Retrieved July 9, 2011. $<$ http://www.albertahealthservices.ca/ahs-nls-otm-2009-02.pdf >.

American Heart Association (AHA). 2005. “Acute Coronary Syndromes." Circulation 112(22 Suppl.). III-55III-72.

Arnold, J.M., P. Liu, D. Demers, P. Dorian, N. Giannetti et al. and the Canadian Cardiovascular Society. 2006. "Canadian Cardiovascular Society Consensus Conference Recommendations on Heart Failure 2006: Diagnosis and Management." Canadian Journal of Cardiology 22(1): 23-45.

Brouwers, M., M.E. Kho, G.P. Browman, F. Cluzeau, G. Feder et al., on behalf of the AGREE Next Steps Consortium. 2010. "AGREE II: Advancing Guideline Development, Reporting, and Evaluation in Healthcare." Canadian Medical Association Journal 182(8): E839-42.

Brown, L.H., K. Collins, J.E. Gough and N.H. Benson. 1999. "An Evidence-Based Evaluation of EMS Protocols." Prehospital Emergency Care 3(1): 31-36.

Canadian Medical Association Journal (CMAJ). 2009. Clinical Practice Guidelines Published in CMAJ. Retrieved July 9, 2011. <http://www.cmaj.ca/site/misc/service/guidelines.xhtml>.

Cone, D.C. 2007. "Knowledge Translation in the Emergency Medical Services: A Research Agenda for Advancing Prehospital Care." Academic Emergency Medicine 14(11): 1052-57.

EAST Ad Hoc Committee on Guideline Development. 1998. “Practice Management Guidelines for Trauma from the Eastern Association for the Surgery of Trauma." Journal of Trauma 44: 941-42.

Eddy, D.M. 1990."Clinical Decision Making: From Theory to Practice. Practice Policies - Guidelines for Methods." Journal of the American Medical Association 263(13): 1839-41.

EMS Chiefs of Canada (EMSCC). 2006. The Future of EMS in Canada: Defining the Road Ahead. Retrieved July 9, 2011. <http://www.semsa.org/Downloadables/EMSCC-Primary\%20Health\%20Care.pdf>.

Field, M.J. and K.N. Lohr, eds. 1992. Institute of Medicine Guidelines for Clinical Practice: From Development to Use. Washington, DC: National Academy Press.

Gazmuri, R.J., J.P. Nolan, V.M. Nadkarni, H.R. Arntz, J.E. Billi et al. 2007.“Scientific Knowledge Gaps and Clinical Research Priorities for Cardiopulmonary Resuscitation and Emergency Cardiovascular Care Identified During the 2005 International Consensus Conference on ECC and CPR Science with Treatment Recommendations. A Consensus Statement from the International Liaison Committee on Resuscitation; the American Heart Association Emergency Cardiovascular Care Committee; the Stroke Council; and the Cardiovascular Nursing Council." Resuscitation 75(3): 400-11.

Graham, I.D., J. Logan, M.B. Harrison, S.E. Straus, J. Tetroe et al. 2006. “Lost in Knowledge Translation: Time for a Map?" Journal of Continuing Education in the Health Professions 26(1): 13-24.

Huberman, M. 1987. “Steps towards an Integrated Model of Research Utilization.” Science Communication 8: 586-611. 


\section{Towards National Evidence-Informed Practice Guidelines for Canadian EMS}

Jensen, J.L., D.A. Petrie, E. Cain and A.H. Travers. 2009."The Canadian Prehospital Evidence-Based Protocols Project: Knowledge Translation in Emergency Medical Services Care." Academic Emergency Medicine 16(7): 668-73.

Myers, J.B., C.M. Slovis, M. Eckstein, J.M. Goodloe, S.M. Isaacs et al. 2008. "Evidence-Based Performance Measures for Emergency Medical Services Systems: A Model for Expanded EMS Benchmarking. A Statement Developed by the 2007 Consortium of U.S. Metropolitan Municipalities' EMS Medical Directors." Prehospital Emergency Care 12(2): 141-51.

National Heart, Lung and Blood Institute, National Institutes of Health. 2007. Section 5, Managing Exacerbations of Asthma. Retrieved July 9, 2011. <http://www.nhlbi.nih.gov/guidelines/asthma/11_sec5_exacerb.pdf>.

National Highway Traffic Safety Administration, Federal Interagency Committee on EMS and National EMS Advisory Council. 2008. From Evidence to EMS Practice: Building the National Model. Conference, Washington, DC.

Sackett, D.L., W.M. Rosenberg, J.A. Gray et al. 1996. "Evidence-Based Medicine: What It Is and What It Isn't." Editorial. British Medical Journal 312: 71-72.

Timerman, S., M.M.C. Gonzalez, E.T. Mesquita, L.R.B. Marques, J.A.F. Ramires et al. 2006. “The International Liaison Committee on Resuscitation (ILCOR). Roll in Guidelines 2005-2010 for Cardiopulmonary Resuscitation and Emergency Cardiovascular Care." Arquivos Brasileiros de Cardiologia 87: e201-08. 